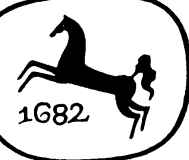

DAS HISTORISCHE DRAMA IN DEUTSCHLAND 
FRIEDRICH SENGLE

\title{
DAS HISTORISCHE DRAMA IN DEUTSCHLAND
}

\author{
GESCHICHTE \\ EINES LITERARISCHEN MYTHOS
}

MCMLXIX

J. B. METZLERSCHE VERLAGSBUCHHANDLUNG STUTTGART 


\section{PAUL KLUCKHOHN}

\section{IN DANKBARKEIT ZUGEEIGNET}

ISBN 978-3-476-98988-8

ISBN 978-3-476-98987-1 (eBook)

DOI 10.1007/978-3-476-98987-1

2. Auflage 1969. Die erste Auflage erschien unter dem Titel "Das deutsche Geschichtsdrama“ (C) 1969 Springer-Verlag GmbH Deutschland

Ursprünglich erschienen bei J. B. Metzlersche Verlagsbuchhandlung und Carl Ernst Poeschel Verlag GmbH in Stuttgart 1952/1969 
VORWORT DES VERLAGES ZUR 2. AUFLAGE

Friedrich Sengle lehnte bisher eine Neuauflage dieses Buches ab. $\mathrm{Er}$ hatte es unter den besonderen Schwierigkeiten der Kriegszeit geschrieben, und eine verbesserte Zweitfassung erschien ihm wünschenswert. Inzwischen steigerte sich die Nachfrage nach dem /seit Jahren vergriffenen) Titel beträchtlich, aber Sengle konnte ihr immer noch nicht entsprechen; denn seine Hauptarbeit (über die „Biedermeierzeit ${ }^{\prime \prime}$ ) differenzierte und erweiterte sich mehr und mehr. Auch begannen schon Pläne, die jenseits dieser demnächst vollendeten Epochendarstellung durchgeführt werden sollen, ihn zu beschäftigen. Wir legen daher, mit der Bitte um Nachsicht, zum 60. Geburtstag Friedrich Sengles einen im Text nur wenig veränderten Neudruck der Jugendarbeit vor. Sie bleibe nach dem Wunsche des Verfassers dem Andenken Paul Kluckhohns gewidmet; denn dieser Gelehrte war sein akademischer Lehrer, und auf dem von Paul Kluckhohn eingeschlagenen Wege, wenn auch mit einer modernen, vielschichtigeren Methode, geht Friedrich Sengle in seinem Lebenswerk über die „Biedermeierzeit" weiter. Der Verlag war Sengle auch als einem der Herausgeber der DVjs. eng verbunden und blickt dankbar auf mehr als zwei Jahrzehnte gemeinsamen Weges zurück, blickt glückwünschend auf die kommenden Jahre voraus.

Herbst 1969 


\title{
EINLEITUNG
}

\author{
I. Teil
}

\section{DIE GRUNDLEGUNG DES DEUTSCHEN GESCHICHTSDRAMAS}

1. Hindernisse für die Entwicklung eines Geschichtsdramas in Deutschland S. 7

Reformation und Humanismus - Barock - Christian Weise

2. Ansätze im Zeitalter der Aufklärung S. 17

Gottscheds und Lessings Theorie - J. E. Schlegel - Bodmer - Lessings und

Chr. F. Weisses Dramen - Klopstock

3. Der Durchbruch zum Geschichtsdrama in der vorklassischen Zeit S. 35 Möser und Goethe - "Götz von Berlichingen “ - Herders Mythos vom Geschichtsdrama - Aufnahme des "Götz " und das Ritterdrama - Lenz Klinger - Sonstige Geschichtsdramen der Zeit - "Egmont - Der junge Schiller - "Don Carlos“ - Schillers Verhältnis zur Geschichte - „Wallenstein"

4. Die klassische Gegenbewegung und Kleist S. 57

Geschichtsdrama und klassisches Programm - Goethes "Natürliche Tochter" - Schillers klassische Dramen - Kleists Geschichtserlebnis - „Prinz von Homburga

5. Der romantische Beitrag zur Entwicklung des Geschichtsdramas S. 68 Die romantische Geschichtsauffassung - Drama und romantische Geschichtsauffassung - Tiecks "Genoveva « Z Zacharias Werner - Brentanos "Die Gründung Prags" - Achim von Arnim - Eichendorff - Zum allgemeinen Charakter des romantisch-historischen Dramas - Die romantische Theorie eines historischen Dramas

$$
\text { II. Teil }
$$

AUSBREITUNG, BLUTE UND VERFALL DES DEUTSCHEN GESCHICHTSDRAMAS

1. Vom Römer- und Ritterstück zum »vaterländischen Drama« der deutschen Staaten S. 109

Allgemeine Grundlagen - Schweiz - Bayern - Brandenburg - Die stärkste Entfaltung in Osterreich - $\mathrm{H}$. von Collin - Vorläufer im 18. Jahrhundert Hormayrs Bestrebungen - J. von Kalchberg - Caroline Pichler M. von Collin 
Seine Stellung in der Geschichte des Dramas - Uberblick über seine dramatische Entwicklung vom Gesichtspunkt des historischen Dramas aus Seine Geschichtsauffassung - Seine Einstellung zum Geschichtsdrama "König Ottokars Glück und Ende“ - "Ein treuer Diener seines Herrn “ "Ein Bruderzwist in Habsburg c - Grillparzers Bedeutung als Geschichtsdramatiker

3. Die dramatische Historie der Restaurationszeit. Immermann S. 145

Ihre Vorbilder in der Interpretation von Tieck - W. von Schütz - F. von Uchtritz - E. Raupach - J. von Auffenberg - Immermanns Weg - Auseinandertreten von historischem und mythischem Drama

4. Grabbe und Büchner S. 158

Der Zusammenbruch des Idealismus und Grabbes Geschichtsbild - Masse Geschichtsheros - Schlacht - Tragödie? - "Marius und Sulla" - "Die Hohenstaufen “ - "Napoleon oder die hundert Tage“ - "Hannibal “ "Hermannsschlacht “ - Der formale Zerfall als Kehrseite von Grabbes historischer Gegenständlichkeit - Büchners nihilistische Geschichtsauffassung - "Dantons Tod"

5. Geschichtsdrama und jungdeutsches Aktualitätsstreben S. 177 Gegen die "tote" Vergangenheit - Das höfische Intriguenstück - Das Dichterdrama - Das historische Lustspiel - Gutzkows "Wullenweber" als Zeitsymptom - Robert Prutz

6. Geschichtsdramatiker im Gefolge Hegels S. 189

Ideelle Geschichte und dramatische Form - Griepenkerl - Julius Mosen Lassalle - J. L. Klein

\section{Hebbel S. 204}

Der individualistische Ausgangspunkt - Verbindung geschichtlicher und individueller Motivierung - Bildungseinflüsse und die Entscheidung zugunsten des "Ganzen " - Die "neue Form der Menschheit - "Maria Magdalene " und das Problem der "Versöhnung - Geringe Bedeutung der Geschichtsinhalte - Absage an das nationalhistorische Drama - Das Revolutionserlebnis und "Agnes Bernauer" - Die drei symbolischen Menschheitsdramen ("Herodes und Mariamne“, "Gyges und sein Ring“, "Nibelungen ") - "Demetrius" als notwendiges Fragment

8. Das historische Drama der Bildungsdichter S. 224

Friedrich Rückert - Otto Ludwig zwischen historischem und psychologischem Drama - Hermann Hettners Einsichten - Allgemeiner Charakter der historischen Bildungsdramen - Erneuerungsversuche - Martin Greif Wildenbruch

\section{Schlu $\beta$}

\section{KRITIK AM GESCHICHTSDRAMA}

Richard Wagners Absage an das Geschichtsdrama - Nietzsches Kampf gegen den Historismus und seine Auswirkung - Naturalistische und neuklassische Zweifel am Geschichtsdrama - Geringes Niveau seiner Vorkämpfer vor dem ersten Weltkrieg - Ende der Sonderentwicklung in Deutschland Anmerkungen S. 250

Register S. 271 